\section{Medical marijuana research}

Research in the medical marijuana field is burgeoning as governments consider changing policy in favour of legalizing the marijuana plant Cannabis sativa. ${ }^{1}$ Like any modern research effort, the gold standard for assessing a new treatment for efficacy compares the treatment to a placebo group. However, controlling for the placebo effects of marijuana may be extremely difficult, and several confounding effects must be considered.

The placebo effect is an improvement in health or behaviour that engulfs a biopsychosocial phenomenon attributable to the placebo and treatment context. On the psychosocial end of the placebo effect spectrum, "the meaning effect" is a similar notion that pertains to the meaning attached to the treatment, as well as the setting and the context of the medical encounter. On the psychobiological end of the spectrum, researchers highlight the central role of expectation, suggestion and conditioning in placeborelated phenomena. New treatments are compared to placebos because placebo effects are very strong - often stronger than the effects of the treatment.

With marijuana, several placebo effects come into play.

Marijuana has a distinct smell and taste, which may elicit classical conditioning responses. Placebo science research holds strong evidence for the effect of classical conditioning related to odour and taste: caffeine-associated stimuli, like the smell and taste of coffee, for example, are shown to increase skin conductance responses and startle eyeblink reflexes in the absence of caffeine. In addition, visual cues associated with smoking marijuana, such as cigarettes, smoke or lighters, may elicit the placebo effect and still remain a factor in even the most well-controlled recent studies. ${ }^{2,3}$

The method of marijuana administration and dose in new trials can carry powerful placebo effects. Will the marijuana be inhaled, injected, or administered topically or sublingually? Placebo science shows that placebo injections work better than placebo pills, and that four placebos work better than two. The strength of the effect of marijuana may differ greatly depending on the method of administration. Medical marijuana research describes several routes of administration, including injecting the psychoactive ingredient delta-9-tetrahydrocannabinol (THC), taking an oral THC capsule or spray, and smoking a marijuana pipe or cigarette. These differing methods of administration will each carry their own placebo effects; grouping such findings together should be avoided.

There is a way to overcome the interference between treatment and placebo effects of marijuana. We can take these lessons from placebo analgesia studies. Studies comparing hidden treatments (e.g., using a computer-controlled infusion machine that is preprogrammed to dispense medication at a desired time) with open administration (where medication is given overtly by a physician or nurse) can eliminate the placebo component. Because patients do not know that the drug is being injected, expectations of a therapeutic response are eliminated. Indeed, a trial conducted by Benedetti and colleagues ${ }^{4}$ showed that a cholecystokinin (CCK) antagonist induced stronger analgesia than a placebo, suggesting that it was a good analgesic. However, this conclusion proved to be erroneous, because a hidden injection of the same CCK antagonist was totally ineffective, showing that it had no intrinsic analgesic pharmacodynamic action; instead, it enhanced placebo-activated release of endogenous opioids. ${ }^{5,6}$ If similar studies are replicated with THC, researchers may be able to elucidate the pain-relieving properties of marijuana's primary psychoactive ingredient.

The marijuana research field is new. Standardized methods need to be developed so researchers can properly evaluate the effectiveness of this treatment for various disorders. Controlling for the powerful placebo effects of marijuana will bring the scientific community one step closer to identifying which conditions this treatment may be most useful for, and how it is best administered.

\section{Natasha K.J. Campbell}

Research coordinator, McGill University, Montréal, Que.

\section{References}

1. Lough S. Growing the evidence base for medical cannabis. CMAJ 2015; 187:955-6.

2. Wilsey B, Marcotte T, Tsodikov A, et al. A randomized, placebo-controlled, crossover trial of cannabis cigarettes in neuropathic pain. J Pain 2008;9:506-21.

3. Ware MA, Wang T, Shapiro S, et al. Smoked cannabis for chronic neuropathic pain: a randomized controlled trial. CMAJ 2010;182:E694-E701.

4. Benedetti F, Amanzio M, Maggi G. Potentiation of placebo analgesia by proglumide. Lancet 1995;346:1231.

5. Benedetti F, Mayberg HS, Wager TD, et al. Neurobiological mechanisms of the placebo effect. $J$ Neurosci 2005;25:10390-402.

6. Benedetti F, Maggi G, Lopiano L, et al. Open versus hidden medical treatments: the patient's knowledge about a therapy affects the therapy outcome. Prev Treatment 2003:6.

CMAJ 2016. DOI:10.1503/cmaj.1150111

\section{Why conscientious objection merits respect}

In his important commentary on respecting conscientious objection to the provision of physician-assisted death (PAD), Dr. Fletcher cites the long-standing tradition of tolerance within the Canadian medical community. ${ }^{1}$ We wish to point out several more reasons for respecting conscientious objection to PAD.

First, there is no duty in Canadian law or medical ethics for physicians to provide access to PAD. In the Carter decision, the Supreme Court of Canada explicitly stated that legalizing PAD did not entail a duty on the part of physicians to provide PAD.

Second, physicians frequently decline to offer treatments because they deem them nonbeneficial or harmful. ${ }^{2}$ Insofar as all refusals of therapy are ultimately justified by the ethical belief that the goal of therapy is to provide benefit and avoid harm, all treatment refusals are matters of conscience.

Third, the ethical justification of PAD remains debatable because it relies on uncertain metaphysical assumptions about the benefit of death ${ }^{3-5}$ and contravenes widely held basic moral intuitions about the inestimable intrinsic value of humans. ${ }^{6}$ Because it remains distinctly possible that $\mathrm{PAD}$ is unethical, objecting physicians should not be forced to facilitate access to PAD for their patients.

Fourth, physicians are ethically complicit when they deliberately refer a patient for a specific intervention. ${ }^{7}$ For 
example, it is clearly objectionable to provide a referral for female genital mutilation. Analogously, if one finds PAD similarly unethical, providing a referral for PAD is highly objectionable and undermines one's moral integrity.

Fifth, respect for conscientious objection upholds the moral integrity of physicians, ${ }^{8,9}$ the foundation for society's confidence in the profession. Disregarding conscientious objection prioritizes moral conformity over moral integrity, undermining the trustworthiness of the profession. Prioritizing moral integrity by respecting conscientious objection can foster quality medical care and enhance patient safety. ${ }^{10}$

\section{Ewan C. Goligher MD PhD \\ Lorenzo Del Sorbo MD}

Interdepartmental Division of Critical Care Medicine, University of Toronto, Toronto, Ont.

Angela M. Cheung MD PhD

Shabbir M.H. Alibhai MD MSc

Department of Medicine, University

Health Network, Toronto, Ont.

Lester Liao MD MTS

Department of Pediatrics, University of

Alberta, Edmonton, Alta.

\section{Alexandra Easson MD MSc}

Department of Surgery, Mount Sinai

Hospital, Toronto, Ont.

Janice Halpern MD

Department of Psychiatry, University of

Toronto, Toronto, Ont.

\section{E. Wesley Ely MD MPH}

Division of Allergy, Pulmonary, and Critical Care Medicine, Department of Medicine, Vanderbilt University School of Medicine, Nashville, Tenn.

\section{Daniel P. Sulmasy MD PhD}

Department of Medicine, University of Chicago, Chicago, Ill.

\section{Stephen W. Hwang MD MPH}

Li Ka Shing Knowledge Institute, St.

Michael's Hospital, Toronto, Ont.

\section{References}

1. Fletcher J. Right to die in Canada: respecting the wishes of physician conscientious objectors. CMAJ 2015;187:1339.

2. Downar J, Warner M, Sibbald R. Mandate to obtain consent for withholding nonbeneficial cardiopulmonary resuscitation is misguided. CMAJ 2016; 188:245-6.

3. Schüklenk U, van Delden JJ, Downie J, et al. Endof-life decision-making in Canada: the report by the Royal Society of Canada expert panel on end-of-life decision-making. Bioethics 2011;25(suppl 1):1-73.

4. Kortenkamp KV, Moore CF. Ethics under uncertainty: the morality and appropriateness of utilitarianism when outcomes are uncertain. Am J Psychol 2014;127:367-82

5. Goligher EC, Ely EW, Sulmasy DP, et al. Physician-assisted suicide and euthanasia in the intensive care unit: a dialogue on core ethical issues. Crit Care Med. In press.
6. Crawshaw R, Rogers DE, Pellegrino ED, et al. Patient-physician covenant. JAMA 1995;273:1553.

7. Magelssen M. When should conscientious objection be accepted? J Med Ethics 2012;38:18-21.

8. Sulmasy DP. What is conscience and why is respect for it so important? Theor Med Bioeth 2008;29:135-49.

9. Lewis-Newby M, Wicclair M, Pope T, et al. An official American Thoracic Society policy statement: managing conscientious objections in intensive care medicine. Am J Respir Crit Care Med 2015;191:219-27.

10. White DB, Brody B. Would accommodating some conscientious objections by physicians promote quality in medical care? JAMA 2011;305:1804-5.

CMAJ 2016. DOI:10.1503/cmaj.1150113

\section{Are we consistent?}

It is interesting that the issue of abortion for sex selection in Canada is raised again in CMAJ in a commen$\operatorname{tary}^{1}$ and research study ${ }^{2}$ in June 2016.

Attempts to arrive at solutions for this problem were suggested variously in the form of laws, education and further research. Do we not as a society and a medical community preach that reproductive health is between a doctor and the patient? Do we not offer abortion selective for Down syndrome (and for other nonlethal anomalies)? Have we not said that other cultures and their values are welcome in Canada and that none is superior to another in our multicultural society? On what basis do we think that abortion for sex selection (as opposed to any other elective abortive procedure) is inappropriate? We have even gone to great lengths to make sure that emergency contraceptive pills are freely available without a prescription. All of this is under the umbrella of "choice."

An immigrant population is exercising its "choice." Is not the solution a rethinking of the issue of a society eliminating its offspring, perhaps for convenience? Abortion for sex selection is a natural progeny of the philosophy of "choice," and it appears inconsistent to question another person's right to "choice" in one room and promote it in another.

John Loge MD

Stettler, Alta.

\section{References}

1. Yasseen AS, Lacaze-Masmonteil T. Male-biased infant sex rations and patterns of induced abortion. CMAJ 2016; 188:640-1

2. Urquia ML, Moineddin R, Jha P, et al. Sex ratios at birth after induced abortion. CMAJ 2016;188: E181-90.

CMAJ 2016. DOI:10.1503/cmaj.1150112

\section{- Correction}

\section{CIHR hikes grants}

CMAJ would like to correct and clarify aspects of the article, "CIHR hikes grants to young researchers," by Paul Webster, published online May 16, 2016.

Paragraph 3 states: "The CIHR [Canadian Institutes of Health Research] rejects both ideas, said Peggy Borbey, director general of CIHR's Investigator-Initiated Research Branch.” In fact, the journalist was paraphrasing Michel Perron, CIHR vice-president external affairs and business development. Regarding the call for a national summit, CIHR President Dr. Alain Beaudet is on the record as stating that CIHR would be "pleased to participate in such an event as appropriate." On the matter of the call for an independent, international review, Perron said there is not yet enough evidence after only one round of grants for such a review, and that these reviews are routinely done by CIHR every five years (next one in 2019/2020). However, Beaudet recently announced that an international, external review of the peer review process is being fast-tracked to late 2017.

Paragraph 5 states: " "We received a troubling signal about the future of research and we want to address it,' Borbey added." In fact, Perron made the statement, not Borbey. It was also a paraphrase, rather than a direct quote.

The second part of this quote states: "We now expect that ECIs [early-career investigators] will do very well in the next round." It is attributed to Borbey, which is correct, but is in fact a paraphrase, not a direct quote.

$C M A J$ sincerely apologizes for these errors.

\section{Reference}

1. Webster P. CIHR hikes grants to young researchers. CMAJ 2016;188:647.

CMAJ 2016. DOI:10.1503/cmaj.1150110 